\title{
Identification of Individuality from Crossed Electro-Immunodiffusion Patterns of Serum
}

\author{
Semchi Kashimura, Kazuo Umetsu and Tsuneo Suzuki \\ Department of Forensic Medicine, Yamagata University School \\ of Medicine, Yamagata 990-23
}

\begin{abstract}
Kashimura, S., Umetsu, K. and Suzukr, T. Identification of Individuality from Crossed Electro-Immunodiffusion Patterns of Serum. Tohoku J. exp. Med., $1979,129(2), 169-176$ - An attempt to identify the individuality from crossed electro-immunodiffusion (CEID) patterns of serum was made by using coefficient of variation (CV), the ratio of standard deviation to mean of ratios of area in couples of corresponding peaks in the CEID patterns. The values of CV in most cases of sera from identical subject were less than 10 except only one case of 10.6. On the contrary, those in most cases of sera from different subjects were more than 20 except a few cases of 14.9 to 20 . No overlap of CV values was observed between the two groups. No significant differences were demonstrated in three groups of sex pairing, i.e., male-male, female-female and female-male. From these results, analysis of CEID patterns by employing CV was found to be available for fairly definite identification as well as differentiation but useless for distinction of sexes in cases of different subjects. —— crossed electroimmunodiffusion (CEID); identification of individuality ; serum protein; coefficient of variation $(\mathrm{CV})$
\end{abstract}

Crossed electro-immunodiffusion (CEID) patterns of human serum seem to be individually unique, and it is thought in general that there is no serum which shows the same pattern as that of others. If it is true and if the patterns do not change for a period, CEID patterns may be useful for identification of individuality. If the same results could be obtained from bloodstains, the usefulness may be wider.

Sweet and Elvins (1976) suggested the possibility of identification of individuality using CEID patterns of bloodstains. But, their analytical method for identification seems to be less useful in actual cases because of the statistical analysis. If an appropriate method is established, CEID patterns of the bloodstains discovered at criminal spots or on clothes of suspected persons may be not only an important clue in the criminal investigation but also a clear evidence in the court as well as fingerprints. But, bloodstains involve many difficulties such as degeneration or decomposition associated with temperature, humidity, time elapsed, materials to which the bloodstains attached, and a large amount of hemoglobin, which is free from reaction and is rather an obstacle for measurement of reacting protein.

Received for publication, September 30, 1978. 
In the present paper, the authors proposed a method available for actual cases by using coefficient of variation (CV) to show dispersion of the ratios of area in each of couples of the corresponding peaks between two plates to be compared. In this method the judgment whether the serum derived from identical subject or not depends on the value of $\mathrm{CV}$. It is expected that the value of CV may be smaller, if the serum derived from identical subject, and it may be larger if it derived from different subjects.

As CEID patterns can be obtained through twice electrophoresis, there may be a certain risk of making artificial errors. If the artificial errors become larger, there may be a risk of misjudge in the identification. Therefore, preliminary assays were carried out to make errors as small as possible.

\section{Materials and Methods}

\section{Blood}

Male and female adult volunteers provided blood. The ages of them ranged from 22 to 37 years. All of them were apparently in good health during the course of the study. The volunteers were drawn blood from their cubital veins twice at an interval of one month. Blood was centrifuged and serum was separated. Protein concentration of the serum was measured by refraction proteometer, and sufficient PBS was added to give a final concentration of $10 \mathrm{mg}$ protein per $\mathrm{ml}$. The concentration of protein must be determined by preliminary assay to be optimal in precipitation test.

The sera were partly used immediately for examination and the rests were preserved in refrigerator at $4^{\circ} \mathrm{C}$ for a month. Blood for one shot examination was also drawn randomly from blood-donors who offered to Blood Transfusion Service Center, Yamagata University Hospital.

\section{Antiserum}

Antiserum to whole human serum was prepared in two rabbits. Each rabbit was injected subcutaneously with an emulsion of $0.5 \mathrm{ml}$ of human serum and $0.5 \mathrm{ml}$ of Freund's complete adjuvant once a week during three months. After the check of precipitin titre to have risen high enough with a small amount of blood from rabbits, they were bled whole blood from the carotid artery under anesthesia. The serum was separated by centrifuge and passed through the membrane filter (pore size $0.3 \mu \mathrm{m}$. Toyo Roshi Co. Ltd.). The antisera were dispensed into $3 \mathrm{ml}$ aliquots and frozen at $-20^{\circ} \mathrm{C}$. Aliquots were thawed before use and they were not refrozen.

\section{Crossed Electro-immunodiffusion (CEID)}

CEID analysis was performed essentially according to the method of Laurell (1965), to which some modifications were added as follows: Barbital-sodium barbital buffer of $\mathrm{pH} 8.6$ and ionic strength 0.03 was boiled with agarose A37 (Nakarai Chemicals Co. Ltd) to form a $1 \%$ solution. Four and half milliliters of molten agarose were poured onto a glass plate $(65 \times 65 \div 2 \mathrm{~mm})$ placed on a horizontal table. After congelation of the agarose, an antigen well $2 \mathrm{~mm}$ in diameter was punched in a corner $15 \mathrm{~mm}$ from adjacent two edges of the gel plate. For electrophoresis in the first dimension (protein separation), $4 \mu l$ of diluted serum was placed in the antigen well, and electrophoresed at $1.5 \mathrm{~mA} / \mathrm{cm}$ for 60 min with barbital-sodium barbital buffer of $\mathrm{pH} 8.6$ and ionic strength 0.06 as bridge buffer. Run of albumin could be followed by adding brom phenol blue to the sample. After the first electrophoresis, the gel plate was cut across $20 \mathrm{~mm}$ from under edge of the plate just above the separated proteins, and the upper part of the gel that did not contain the proteins was removed from the plate. The removed space in the plate was covered uniformly with $3 \mathrm{ml}$ 
molten $\left(56^{\circ} \mathrm{C}\right)$ agarose-antiserum mixture in the proportion of $9: 1$. To determine the optimal concentration of antiserum in agarose-antiserum mixture for routine use of CEID, a series of preliminary assay was also done as described above changing concentration of antigen. After solidification of the agarose-antiserum mixture, electrophoresis in the second dimension was performed at $1 \mathrm{~mA} / \mathrm{cm}$ for $120 \mathrm{~min}$ at an angle of $90^{\circ}$ to the previous direction (Fig. 1). Thereafter, the non-precipitated proteins were removed by wash. ing the plate with $0.15 \mathrm{M} \mathrm{NaCl}$ for $48 \mathrm{hr}$ and then with distilled water for $24 \mathrm{hr}$. The plate was then dried and stained with $0.04 \%$ coomassie brilliant blue R250.

Glass plote $(6.5 \mathrm{~cm} \times 6.5 \mathrm{~cm})$

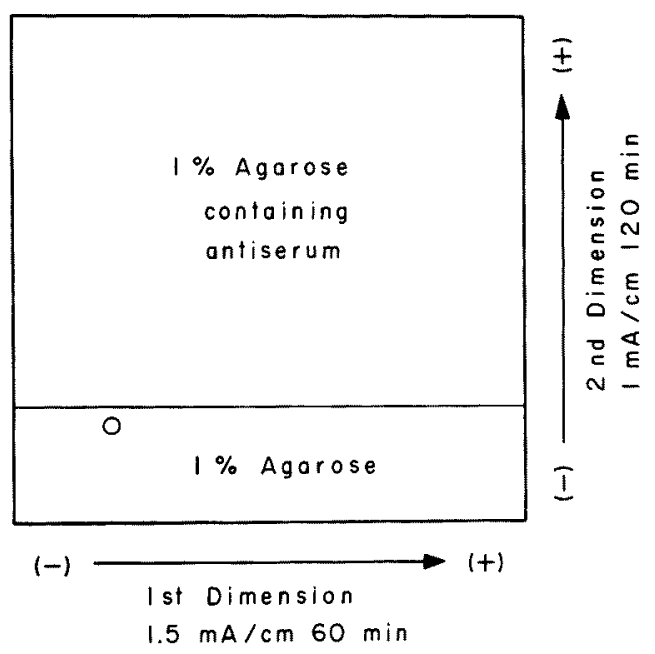

Fig. 1. Sohema of crossed immuno-electrophoresis.

\section{Comparison of CEID patterns}

Contact drawing of contours of precipitation figures was performed for every plate on tracing section paper with millimeter squares (Fig. 2). Areas enclosed by the precipitates were measured by square counting method. Ratios of areas of at least 10 or more corresponding peaks in the two plates to be compared were calculated. To see wideness of dispersion of the ratios, $\mathrm{CV}$ was calculated using both mean and standard deviation of ratios as follows:

$$
\begin{array}{ll}
\mathrm{CV}=\frac{\mathrm{SD}}{\mathrm{MR}} \times 100 \quad \mathrm{MR}: \text { mean of ratios } \\
\mathrm{SD}: & \text { standard deviation of ratios }
\end{array}
$$

It was expected that CV might be small if the two CEID patterns derived from identical subject, and it might be large if they were from different subjects. Determination of the corresponding peaks in two plates depended on biochemical and immunological identifications, that is, relative localization of the peaks in the first dimension and characteristics of shapes of peaks. All the peaks which were not surely judged to be the corresponding patterns were excluded. Some proteins were also excluded for the reasons as follows: prealbumin was very labile; albumin was too large in amount to obtain the optimal precipitation peak in our method: $\gamma$-globulin migrated to cathodic side of the gel; and other proteins having very small peaks caused large errors in measurement of the areas. 


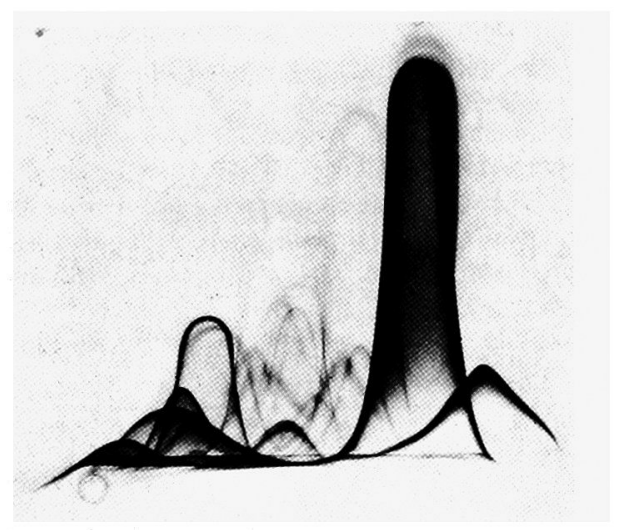

Fig. 2. CEID pattern.

\section{RESULTS}

Comparison of CEID patterns of sera derived from identical subject.

Cases were divided into four groups according to the method of electrophoresis to investigate the influence of various conditions in electrophoresis to CV values. Group I: Two plates which involved identical fresh serum were electrophoresed at the same time in one vessel (control).

Group II: The first serum which had been preserved at $4^{\circ} \mathrm{C}$ for 1 month was electrophoresed at the same time in one vessel with the second serum which was drawn freshly from identical subject after 1 month.

Group III: Both the first and the second serum drawn at an interval of 1 month were individually electrophoresed on the days when they were drawn.

Group IV: A part of serum was electrophoresed immediately and the rest was electrophoresed after preservation at $4^{\circ} \mathrm{C}$ for 1 month.

Distributions of CV and mean in each group are shown in Fig. 3. The range and mean \pm s.D. of $\mathrm{CV}$ were from 3.7 to 7.1 and $4.9 \pm 1.1$ in Group $\mathrm{I}(n=8)$, from 5.6 to 10.6 and $7.9 \pm 1.4$ in Group II $(n=10)$, from 7.1 to 13.4 and $9.5 \pm 2.2$ in Group III $(n=10)$, and from 7.2 to 12.7 and $9.3 \pm 1.9$ in Group IV $(n=10)$, respectively.

It was revealed that both the maximum value and mean of CV in Group II were smaller than those in Groups III and IV which were almost the same each other. Therefore, it is concluded that CEID patterns obtained by electrophoresis in one vessel at the same time are better for comparison than those electrophoresed separately on different occasions. The values of CV in the cases of Group II were smaller than 10 except only one case of 10.6.

Comparison of CEID patterns of sera derived from different subjects.

Distribution of CV in the cases of identical subject and different subjects are shown in Fig. 4. The range and mean \pm S.D. of $\mathrm{CV}$ in the cases of different subjects were from 14.9 to 37.6 and $27.1 \pm 6.6(n=53)$, respectively. These 53 cases between 


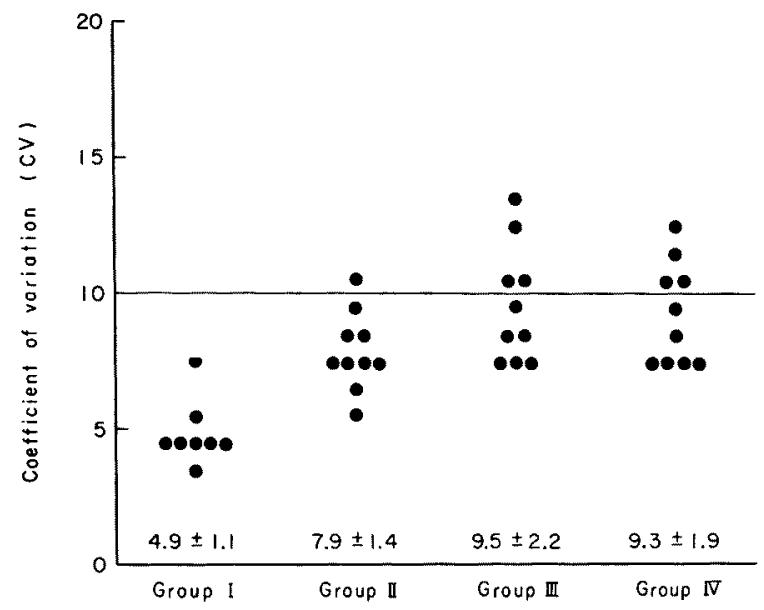

Fig. 3. Distributions of $\mathrm{CV}$ in the groups of identical subjects under various conditions.

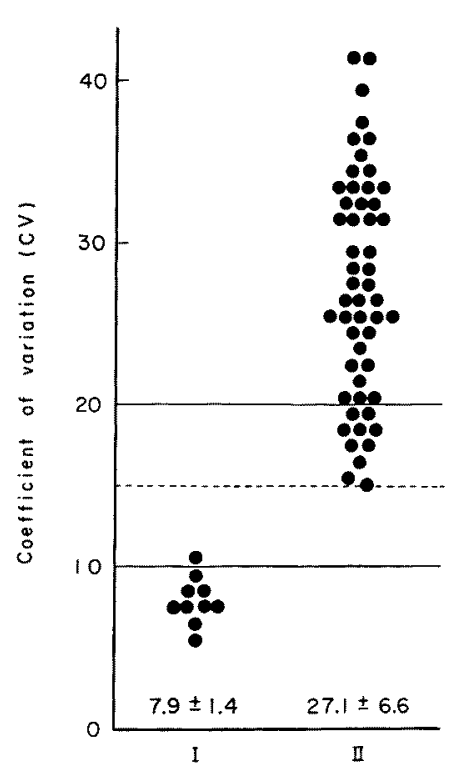

Fig. 4

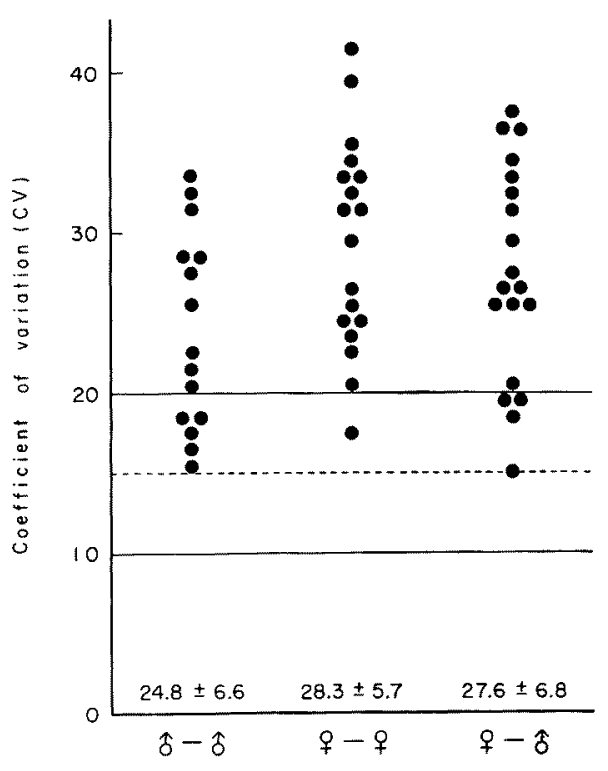

Fig. 5

Fig. 4. Distributions of $\mathrm{CV}$ in the groups of identical subjects (I) and different subjects (II).

Fig. 5. Distributions of $\mathrm{CV}$ in 3 groups by pairing of sexualities.

different subjects were divided into 3 groups by pairing of sexuality, i.e., male-male, female-female and female-male, to study the influence of sexuality to $\mathrm{CV}$ values of each case (Fig. 5). The range and mean 土S.D. of CV were from 15.5 to 39.1 and $24.8 \pm 7.0$ in the group of male-male $(n=16)$, from 17.2 to 39.0 and $28.3 \pm 5.7$ in female-female $(n=18)$, and from 14.9 to 36.2 and $27.8 \pm 6.8$ in female-male $(n=19)$, 
respectively. As can be seen, both the range and mean of CV were almost the same each other, and no significant differences were observed among them. The values of $\mathrm{CV}$ between different subjects were larger than 20 except only a few cases of 15 to 20 .

No overlap was observed between the values of $\mathrm{CV}$ from the cases of different subjects and those of identical subjects.

\section{Discussion}

Bloodstains have very important value in forensic practice, and most researches on the serologic characterization of bloodstains have been directed toward improvement and extension of typing of erythrocyte antigens. But, the value of detection of blood groups may decrease in cases where the blood groups are identical between the suspected and the victim.

Human serum contains a large number of individual proteins. Schultze and Heremans (1966) listed 34 well documented proteins. Immunoelectrophoresis against anti-whole human serum reveals a large number of protein components in serum, the number of which depends on the antiserum. Ressler (1960) reported a new technique, two-dimensional electrophoresis of antigens with antibody containing buffer. Laurell (1965) devised antigen/antibody crossed electrophoresis which characterized the serum proteins further and enabled quantitative assessment of their individual concentrations. Weeke (1970) succeeded in identifying 26 precipitates of 42 precipitation arcs according to Laurell's method using known antigens and antibodies. Sweet and Elvins (1976) demonstrated the CEID patterns of bloodstains by using the modified Laurell's method, and suggested possibility of identification of individuality. They noticed the differences of peak height among corresponding protein components in the patterns to be compared. Certainly, the difference of peak height may be significant in the quantitative assay if the bases of peaks are all equal in width and the shapes are symmetrical such as the well-known Laurell's rocket (1966). However, the width of bases of peaks and the peak height are not always equal even if the amount of the corresponding protein components is equal, because CEID patterns are obtained by two-dimensional electrophoretic developments. Moreover, the shapes of some peaks are not symmetrical. For these reasons, it is considered to be rational to compare peak area rather than peak height (Clarke and Freeman 1966, 1968).

In the present paper the authors proposed an analytical method employing the coefficient of variation $(\mathrm{CV})$, which is a common parameter used in statistical analysis, to observe the dispersion rate of ratios of areas in each couple of the corresponding peaks in comparison of patterns. This conception is based on the principle as follows. When the sera were derived from identical subject, quantitative distribution of each protein components must be almost equal. Theoretically, the ratios of area in each couple of corresponding peaks in the CEID patterns are all equal without dispersion. Contrarily, as the distribution of protein components may be various in the sera from different subjects, the ratios of areas 
may be also various with wide dispersion. Consequently, CV is small if the sera were derived from identical subject, and it is large if they were from different subjects.

As CEID patterns are obtained through twice electrophoresis, there are many risks of artificial error which may change the patterns and $\mathrm{CV}$. There are also many factors to change the pattern, such as different reactivity or titre among antisera employed, quality of agarose, chemical materials and distilled water, concentration, $\mathrm{pH}$ and ionic strength of buffer systems, amperage or voltage of electric current in electrophoresis and so on. The difference due to each factor may be very slight and insignificant, but accumulation of these slight differences may result in significant change of pattern, and therefore, may change CV. It was considered that the best way to eliminate the risk of errors as far as possible was to electrophorese the sera at the same time using the same agarose solution, the same buffer system and the same amperage or voltage in one vessel. But, samples can't be obtained always at the same time, so they need to be preserved. Then, in order to know the influence of preservation, $\mathrm{CV}$ value was compared between a group which was electrophoresed together after preservation and the other group which was electrophoresed separately without preservation. As can be seen in Fig. 3, both the maximum value and mean of $\mathrm{CV}$ were smaller in the former (Group II) than in the latter (Group III). From the distribution of CV in Group IV, which was almost the same as that in Group III, it was found that the difference of CV distribution was due to separate electrophoresis rather than preservation. Therefore, for the comparison of CEID patterns, the sera are desirable to be electrophoresed together in one vessel even in cases of preservation. Data in Figs. 4 and 5 were all based on the $\mathrm{CV}$ values which were obtained by electrophoresing together. As can be seen in Fig. 4, the values of $\mathrm{CV}$ in most cases of identical subjects were smaller than 10 except only one case of 10.6. On the contrary, those in most cases between different subjects were larger than 20 . The case of less than 15 was only one, of which CV was 14.9. No overlap was observed between the two groups.

From these results, it is probable that the serum with $\mathrm{CV}$ value less than 10 was derived from identical subject, and that with CV value more than 20 was derived from different subjects, and it may be possible that the serum with CV value between 10 and 15 was derived from identical subject and that between 15 and 20 was derived from different one.

No significant differences were observed among the three groups of male-male, female-female and female-male (Fig. 5). This may be explained from the assumption that there are few genes related with sex chromosome to control each protein component.

In our present study, all peaks in CEID pattern of serum or bloodstain were treated as a group, so that the characteristics of each peak were all neglected. Nevertheless, this method is considered to be useful as a means of identification of individuality. No other methods have been found available for actual cases at the present time. 


\section{References}

1) Clarke, H.G.M. \& Freeman, T. (1966) A quantitative immunoelectrophoretic method (Laurell electrophoresis). Prot. biol. Fluids. 14, 503-509.

2) Clarke, H.G.M. \& Freeman, T. (1968) Quantitative immunoelectrophoresis of human serum proteins. Clin. Sci., 35, 403-413.

3) Laurell, C.B. (1965) Antigen-antibody crossed electrophoresis. Analyt. Biochem., 10, 358-361.

4) Laurell, C.B. (1966) Quantitative estimation of proteins by electrophoresis in agarose gel containing antibodies. Analyt. Biochem., 15, 45-52.

5) Ressler, N. (1960) Two dimensional electrophoresis of antigens with antibody containing buffer. Clin. chim. Acta, 5, 795-800.

6) Schultze, H.E. \& Heremans, J.F. (1966) Molecular Biology of Human Proteins. Vol. 1, Elsevier Publishing Co., Amsterdam.

7) Sweet, G.H. \& Elvins, J.W. (1976) Studies by crossed electroimmunodiffusion of the individuality and sexual origin of bloodstains. J. forens. Sci., 5, 498-509.

8) Weeke, B. (1970) The serum proteins identified by means of the Laurell crossed electrophoresis. Scand. J. clin. Lab. Invest, 25, 269-275. 